\title{
Transient Receptor Potential Vanilloid 4 Regulation of Adenosine Triphosphate Release by the Adenosine Triphosphate Transporter Vesicular Nucleotide Transporter, a Novel Therapeutic Target for Gastrointestinal Baroreception and Chronic Inflammation
}

\author{
Hiroshi Mihara a,b Ammar Boudakac Makoto Tominagad Toshiro Sugiyama ${ }^{\mathrm{e}}$ \\ ${ }^{a}$ Center for Medical Education and Career Development, Graduate School of Medicine and Pharmaceutical \\ Sciences, University of Toyama, Toyama, Japan; ${ }^{b}$ Department of Gastroenterology, Graduate School of Medicine \\ and Pharmaceutical Sciences, University of Toyama, Toyama, Japan; ' ${ }^{\mathrm{D}}$ Department of Physiology, College of \\ Medicine and Health Sciences, Sultan Qaboos University, Muscat, Oman; ${ }^{\mathrm{d}}$ Division of Cell Signaling, National

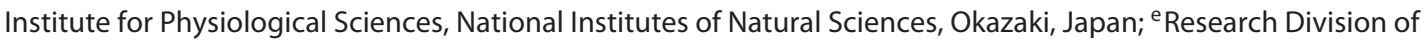 \\ Molecular Targeting Therapy and Prevention of GI Cancer, Hokkaido University, Sapporo, Japan
}

\section{Keywords}

Gastrointestinal epithelium · Adenosine triphosphate ·

Transient receptor potential vanilloid 4 . Clodronate

\begin{abstract}
Background: Transient receptor potential vanilloid 4(TRPV4) is activated by stretch (mechanical), warm temperature, some epoxyeicosatrienoic acids, and lipopolysaccharide. TRPV4 is expressed throughout the gastrointestinal epithelia and its activation induces adenosine triphosphate (ATP) exocytosis that is involved in visceral hypersensitivity. As an ATP transporter, vesicular nucleotide transporter (VNUT) mediates ATP storage in secretory vesicles and ATP release via exocytosis upon stimulation. Summary: TRPV4 is sensitized under inflammatory conditions by a variety of factors, including proteases and serotonin, whereas methylationdependent silencing of TRPV4 expression is associated with various pathophysiological conditions. Gastrointestinal epithelia also release ATP in response to hypo-osmolality or acid
\end{abstract}

through molecular mechanisms that remain unclear. These synergistically released ATP could be involved in visceral hypersensitivity. Low concentrations of the first generation bisphosphate, clodronate, were recently reported to inhibit VNUT activity and thus clodronate may be a safe and potent therapeutic option to treat visceral pain. Key Messages: This review focuses on: (1) ATP and TRPV4 activities in gastrointestinal epithelia; (2) factors that could modulate TRPV4 activity in gastrointestinal epithelia; and (3) the inhibition of VNUT as a potential novel therapeutic strategy for functional gastrointestinal disorders.

(C) 2019 The Author(s)

Published by S. Karger AG, Basel

\section{Introduction}

Visceral hypersensitivity to stretch (mechanical) [1], temperature [2], and acid [3] plays a role in functional gastrointestinal disorders, through molecular mechanisms that remain unclear. For example, in irritable bow-

\begin{tabular}{ll}
\hline KARGER & $\begin{array}{l}\text { ( } 2019 \text { The Author(s) Karger } \\
\text { Published by S. Karger AG, Basel Open caccess }\end{array}$ \\
E-Mail karger@karger.com & $\begin{array}{l}\text { This article is licensed under the Creative Commons Attribution- } \\
\text { NonCommercial-NoDerivatives 4.0 International License (CC BY- } \\
\text { www.karger.com/dig }\end{array}$ \\
$\begin{array}{l}\text { NC-ND) (http://www.karger.com/Services/OpenAccessLicense). } \\
\text { Usage and distribution for commercial purposes as well as any dis- } \\
\text { tribution of modified material requires written permission. }\end{array}$
\end{tabular}


el syndrome (IBS), repetitive rectal painful distention induces rectal hypersensitivity [1]. Thermal hypersensitivity was reported in IBS patients and is positively correlated with increased intestinal membrane permeability [2].

As a stretch-activated nonselective cation ion channel, transient receptor potential vanilloid 4 (TRPV4) can induce visceral hypersensitivity [4]. We found that TRPV4 and an adenosine triphosphate (ATP) transporter, vesicular nucleotide transporter (VNUT), are both expressed throughout gastrointestinal epithelia and that a VNUT inhibitor, the first-generation bisphosphonate clodronate, inhibits TRPV4-induced ATP release [5].

In this review, we consider: (1) ATP and TRPV4 activities in gastrointestinal epithelia; (2) possible factors that modulate TRPV4 activity in gastrointestinal epithelia; and (3) inhibition of VNUT as a novel therapeutic strategy for functional gastrointestinal disorders.

\section{ATP and TRPV4 in Gastrointestinal Epithelia}

ATP signaling plays an important role in a variety of gut activities. Purinergic receptors can be divided into the P2X family of ionotropic receptors and the P2Y family of G protein-coupled receptors, both of which are involved in visceral hypersensitivity [6]. In P2X3 knockout mice, ATP release in response to mechanical distension of the esophagus and stomach is similar to that seen for wild-type (WT) mice, whereas activation of afferent nerve fibers is attenuated relative to WT mice [7]. Meanwhile, a P2X3 agonist was shown to stimulate mechanosensitive vagal afferent nerves in mouse stomach and esophagus [8], suggesting that ATP release induced by mechanical stimuli and the $\mathrm{P} 2 \mathrm{X} 3$ receptor play important roles in baroreception in the gut. Based on the possibility that epithelial ATP release in response to luminal distension could act on purinergic receptors in submucosal nerves to transduce mechanical signals to the CNS or induce enteric reflex, especially under inflammatory conditions [6], we focused on ATP release upon epithelial TRPV4 activation.

TRPV4 was originally identified as a hypoosmolaritysensitive ion channel that is activated by mechanical stimuli, warm temperature, and epoxyeicosatrienoic acid, the levels of which are increased in inflammatory conditions [4]. In the upper gastrointestinal tract, TRPV4 is expressed in the extrinsic nerves as well as esophageal and gastric epithelia $[9,10]$. TRPV4 activation promotes VNUT-mediated ATP release in the esophagus. Heat stimulus $\left(>38.5^{\circ} \mathrm{C}\right)$ significantly increases ATP release from WT cultured mouse esophageal keratinocytes in a manner that is dependent on TRPV4 expression [9].

Gastrointestinal Epithelial TRPV4 and

ATP Inhibition
TRPV4 can be activated by acidity, and enhanced writhing behavior was observed within $10 \mathrm{~min}$ of injection of $0.7 \%$ acetate into the abdomen of mice. These effects are suppressed in TRPV 4 knockout $\left(\operatorname{Trpv} 4^{-/-}\right)$mice relative to WT mice [11]. In human, stimulation of esophageal epithelial cells by acid promotes ATP release [12], whereas TRPV4-mediated increases in $\left[\mathrm{Ca}^{2+}\right]_{\mathrm{i}}$ are suppressed by extracellular protons ( $\mathrm{pH}$ 5.0) [13]. This discrepancy could be attributed to the ability of acidic conditions to induce acid-sensing ion channel-like currents in WT or TRPV4 ${ }^{-/}$esophageal keratinocytes independent of TRPV4. Gastrointestinal epithelia cells release ATP in response to not only chemical but also acid, temperature, and hypo-osmolality (Fig. 1) [14].

The VNUT modulates the storage of ATP in secretory vesicles and ATP release from these vesicles via exocytosis. TRPV4 can induce VNUT-mediated ATP exocytosis in the human gastric epithelial cell line GES-1 and activate enteric neurons [5]. Overall, the high concentrations of arachidonic acid metabolites in tissues, high temperatures, hypo-osmolality, and acidity of GI fluid may elicit ATP release from GI epithelia that in turn overstimulates GI nerves (Fig. 2).

Duodenal and intestinal microinflammation and increased permeability are pathophysiological conditions that are associated with functional dyspepsia (FD) and IBS, respectively $[15,16]$. Thermal hypersensitivity in IBS is linked to increased intestinal permeability [2]. TRPV4 activation increases epithelial permeability due to endocytosis of tight junction proteins, especially claudin 4 , as was shown in the mammary cell line HC11 [17], and also increases the permeability of the intestinal epithelial cell line IEC6 [18]. Acid infusion in the duodenum induces symptoms in a subset of FD patients, but not in control patients [19], whereas endogenous TRPV4 agonists such as 5,6-EET and 8,9-EET increase TRPV4-mediated epithelial increased permeability and thus might be involved in visceral hypersensitivity under microinflammation conditions. Although there are no reports of TRPV4 inhibitors being administered to humans, in mice and rats such inhibitors produced no serious adverse events [20], and thus might be valuable for controlling the gut hypersensitivity.

In mouse and human colon, TRPV4 localizes to epithelial cells and as yet unidentified cells of the submucosal and muscular layers. TRPV4 agonists can increase intracellular calcium concentrations and promote chemokine release in human colon cancer cell lines and induce colitis in mice [21]. Although TRPV4 is expressed in both the epithelium and enteric neurons in the colon and 


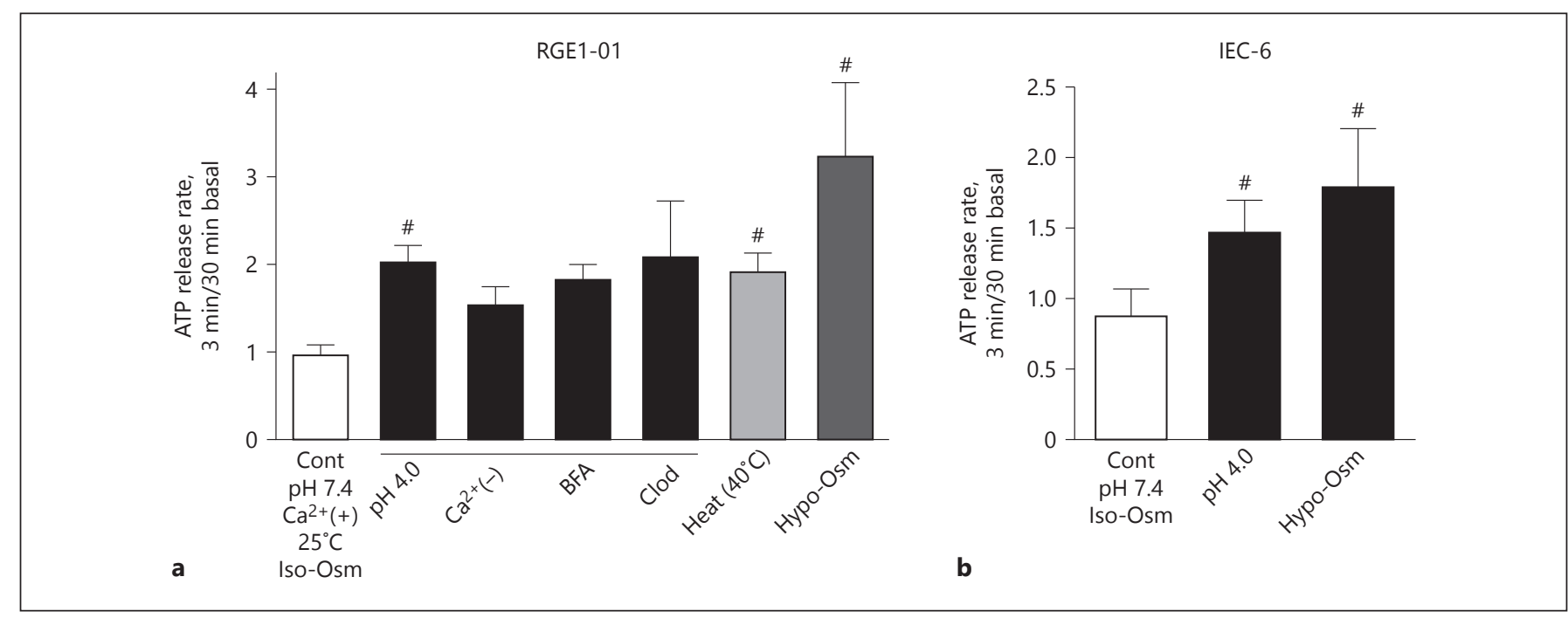

Fig. 1. Physical stimuli-induced ATP release from gastrointestinal epithelia. a Release of ATP from the rat gastric epithelial cell line RGE1-01 in response to acid ( $\mathrm{pH} 4.0)$, heat $\left(40^{\circ} \mathrm{C}\right)$, and hypo-osmolality (half-normal saline). Acid-induced ATP release was not inhibited in the absence of extracellular $\mathrm{Ca}^{2+}$, the vesicle-traffick- ing inhibitor BFA, or the VNUT inhibitor Clod. b Rat IEC-6 also release ATP in response to acid or hypo-osmolality ( ${ }^{\#} p<0.05$ vs. Cont). ATP, adenosine triphosphate; BFA, brefeldin A; Clod, clodronate; IEC, intestinal epithelia cells; Cont, control.

and protease-activated receptor 2 . We showed that protease-activated receptor 2 expressed in the esophageal epithelium is activated by proteases such as trypsin and tryptase and that treatment of mouse esophageal keratinocytes with trypsin enhances ATP release via TRPV4 activation [26]. Serotonin and histamine increase TRPV4 expression in mouse colon neurons [27], whereas tumor necrosis factor- $\alpha$ and interleukin-17 can enhance TRPV4 expression in some neuronal cell types such as DRG [20, 25].

On the other hand, gastric epithelial cells infected with Helicobacter pylori and gastric cancer cells were shown to have suppressed TRPV4 expression due to enhanced methylation of the TRPV4 gene [10]. Emerging evidence shows that dysbiosis is involved in various diseases such as IBS that involve modulations of epithelial permeability, metabolites, and immune system function [28]. Such enhanced or suppressed function of TRPV4 can be a molecular mechanism by which visceral hypersensitivity or blunting occurs (Fig. 2).

\section{Possible TRPV4 Modulators in Gastrointestinal Epithelia}

As mentioned earlier, TRPV4 is activated by hypoosmolarity, mechanical stimuli, warm temperature, and epoxyeicosatrienoic acid [4]. Interestingly, lipopolysaccharides produced by commensal bacteria also directly activate TRPV4 [24]. Moreover, several factors are known to enhance TRPV4 function, including proteases, serotonin, histamine, tumor necrosis factor- $\alpha$, interleukin-17 [25],

\section{VNUT Inhibition as a Novel Therapeutic Strategy for Functional Gastrointestinal Disorders}

Blockage of nerve pathways that connect TRPV4 to ATP and ATP to a purinergic receptor should ameliorate visceral pain. Although TRPV4 inhibition had no serious systemic adverse events in mice and rats [20], in humans 


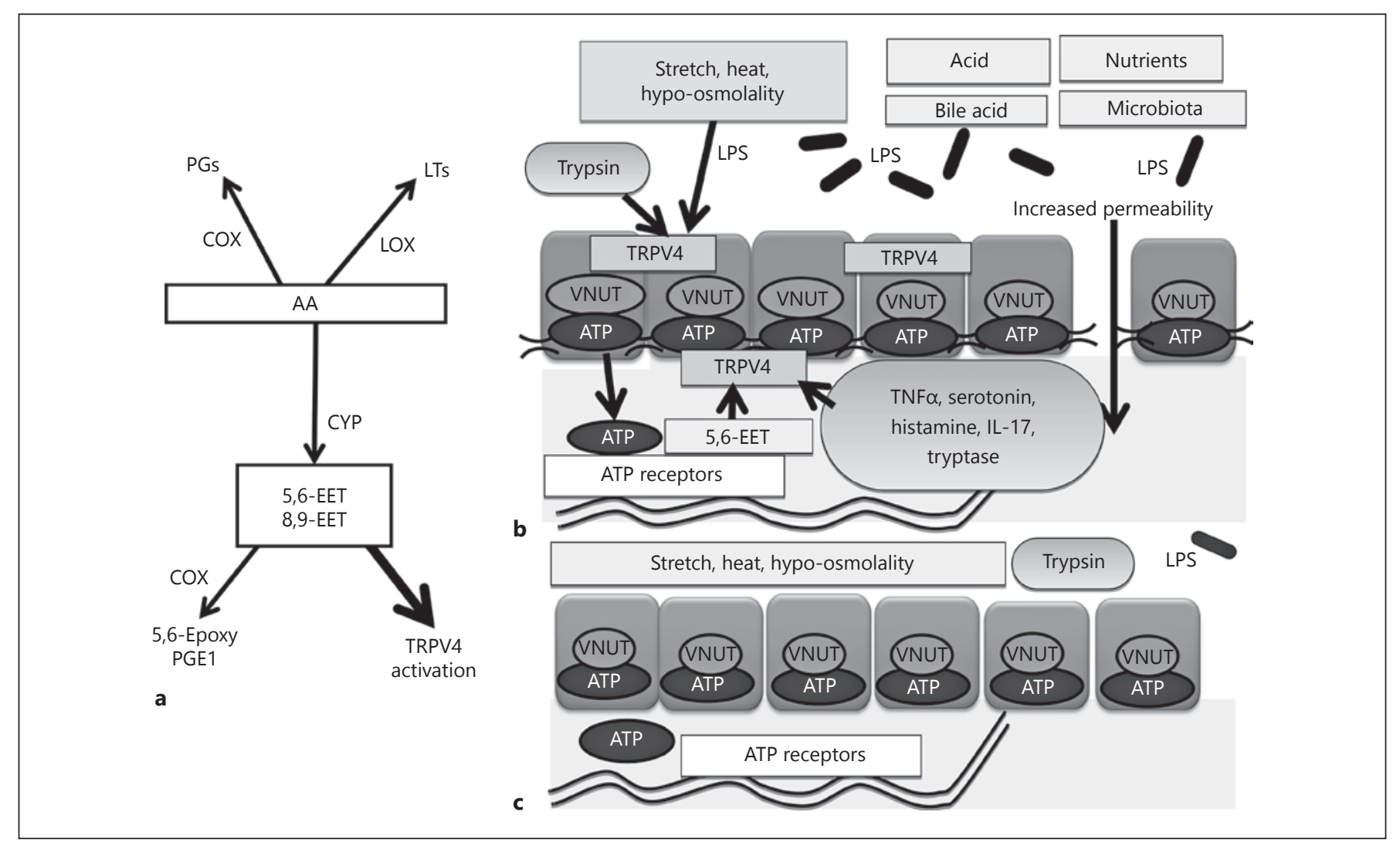

Fig. 2. Proposed molecular mechanism of visceral hypersensitivity or blunting with TRPV4 enhancement or suppression. a Formation of major metabolites generated from the AA cascade. CYP enzymes convert arachidonic acid into EETs. Increased amounts of 5,6-EET or 8,9-EET then activate TRPV4. $\mathbf{b}$ TRPV4 expressed in gastrointestinal epithelia is activated by stretch, heat, hypo-osmolality, LPS or the endogenous activators (5,6-EET and 8,9EET). Several factors (e.g., proteases such as trypsin and tryptase, TNFa, serotonin, histamine, IL-17) enhance TRPV4 function. TRPV4 activation induces VNUT-mediated ATP exocytosis and

such inhibition could promote physiological dysfunction. P2X7 receptor antagonists such as AZD-9056 were not effective in mitigating Crohn's disease symptoms. $\mathrm{P} 2 \mathrm{X} 3$ receptor antagonists have been recommended as a possible treatment for IBS [6].

The SLC17A9 gene encodes the VNUT. VNUT knockout mice appear to be healthy but have reduced amounts of vesicular storage and release of ATP and are resistant to acute inflammatory pain [29]. Recently, the first-generation bisphosphate clodronate was shown to specifically inhibit VNUT activity at low concentrations, suggesting that this compound could be an effective agent to treat chronic pain [30]. Indeed, intravenous injection of clodronate into mice attenuated inflammatory pain by about increases cellular permeability. Acid also induces ATP release via another mechanism to induce visceral hypersensitivity. c Methylation-silencing of TRPV4 expression decreases epithelial sensitivity to physiological stimuli resulting in diminished visceral responses. AA, arachidonic acid; CYP, Cytochrome P450; EET, epoxyeicosatrienoic acids; TRPV4, transient receptor potential vanilloid 4; LPS, lipopolysaccharides; VNUT, vesicular nucleotide transporter; ATP, adenosine triphosphate; TNFa, tumor necrosis factor- $\alpha$; IL-17, interleukin-17; PG, prostaglandin; LT, leukotriene; COX, cyclooxygenase; LOX, lipoxygenase.
$40 \%$ relative to untreated animals without any observed adverse effects and had an analgesic effect that was stronger than diclofenac and comparable to tramadol [29]. The clodronate Bonefos has been used worldwide for over 30 years to treat osteoporosis, bone metastasis pain, and inflammatory bowel disease [30]. Intravenous or oral administration of clodronate has been shown to have analgesic effects and does not produce severe adverse events. Generic versions of clodronate are now available. However, there are currently no clinical trials to evaluate the efficacy of clodronates for treating functional gastrointestinal disorders, in part due to the widespread use of these compounds for non-gastrointestinal purposes and the lack of approval in Japan for their use as analgesic agents. 


\section{Conclusion}

In recent years, epithelial cells were shown to function as sensory tissues via the activity of ion channel receptors such as TRPV4. Future studies will likely reveal additional pressure-, temperature-, and acid-sensing mechanisms that function in digestive tract epithelia and determine whether inhibition of VNUT via clodronate could serve as an effective treatment for visceral pain.

\section{Acknowledgments}

We thank T. Kozawa for her technical assistance. This review is based on the core symposium "New development of gastrointestinal functional disorder-Pathophysiology and target molecules of FD" held in 2018 and "New development of gastrointestinal functional disorder-Molecular pathogenesis and new development of IBS" presented at the 2019 meeting of The Japan Gastroenterological Association.

\section{Disclosure Statement}

The authors have no conflicts of interest to disclose.

\section{References}

1 Nozu T, Kudaira M, Kitamori S, Uehara A. Repetitive rectal painful distention induces rectal hypersensitivity in patients with irritable bowel syndrome. J Gastroenterol. 2006 Mar;41(3):217-22.

2 Zhou Q, Zhang B, Verne GN. Intestinal membrane permeability and hypersensitivity in the irritable bowel syndrome. Pain. 2009 Nov; 146(1-2):41-6.

3 Modlin IM, Hunt RH, Malfertheiner P, Moayyedi P, Quigley EM, Tytgat GN, et al.; Vevey NERD Consensus Group. Diagnosis and management of non-erosive reflux disease-the Vevey NERD Consensus Group. Digestion. 2009;80(2):74-88.

4 Balemans D, Boeckxstaens GE, Talavera K, Wouters MM. Transient receptor potential ion channel function in sensory transduction and cellular signaling cascades underlying visceral hypersensitivity. Am J Physiol Gastrointest Liver Physiol. 2017 Jun;312(6):G635-48.

5 Mihara H, Uchida K, Koizumi S, Moriyama Y. Involvement of VNUT-exocytosis in transient receptor potential vanilloid 4-dependent ATP release from gastrointestinal epithelium.PLoSOne.2018Oct;13(10):e0206276.

6 Burnstock G. Purinergic Signalling: therapeutic Developments. Front Pharmacol. 2017 Sep;8:661.

7 McIlwrath SL, Davis BM, Bielefeldt K. Deletion of $\mathrm{P} 2 \mathrm{X} 3$ receptors blunts gastro-oesophageal sensation in mice. Neurogastroenterol Motil. 2009 Aug;21(8):890-e66.

8 Page AJ, Martin CM, Blackshaw LA. Vagal mechanoreceptors and chemoreceptors in mouse stomach and esophagus. J Neurophysiol. 2002 Apr;87(4):2095-103.

9 Mihara H, Boudaka A, Sugiyama T, Moriyama Y, Tominaga M. Transient receptor potential vanilloid 4 (TRPV4)-dependent calcium influx and ATP release in mouse oesophageal keratinocytes. J Physiol. 2011 Jul;589(Pt 14):3471-82.

10 Mihara H, Suzuki N, Muhammad JS, Nanjo S, Ando T, Fujinami $\mathrm{H}$, et al. Transient receptor potential vanilloid 4 (TRPV4) silencing in Helicobacter pylori-infected human gastric epithelium. Helicobacter. 2017 Apr;22(2):22.

11 Suzuki M, Mizuno A, Kodaira K, Imai M. Impaired pressure sensation in mice lacking TRPV4. J Biol Chem. 2003 Jun;278(25): 22664-8.

12 Ma J, Altomare A, Rieder F, Behar J, Biancani P, Harnett KM. ATP: a mediator for HCl-induced TRPV1 activation in esophageal mucosa. Am J Physiol Gastrointest Liver Physiol. 2011 Dec;301(6):G1075-82.

13 Shikano M, Ueda T, Kamiya T, Ishida Y, Yamada T, Mizushima T, et al. Acid inhibits TRPV4-mediated $\mathrm{Ca}^{2+}$ influx in mouse esophageal epithelial cells. Neurogastroenterol Motil. 2011 Nov;23(11):1020-8, e497.

14 Mihara H, Muhammad JS, Suzuki N, Tabuchi Y, Sugiyama T. Gastrointestinal Epithelia Could Be Luminal Sensors for Chemical, Hypo Osmolality, Acid, Temperature and Stretch via ATP Release. Gastroenterology. 2015;148(4):S-91.

15 Miwa H, Oshima T, Tomita T, Fukui H, Kondo T, Yamasaki T, et al. Recent understanding of the pathophysiology of functional dyspepsia: role of the duodenum as the pathogenic center. J Gastroenterol. 2019 Apr;54(4):30511.

16 Zhang L, Song J, Hou X. Mast Cells and Irritable Bowel Syndrome: From the Bench to the Bedside. J Neurogastroenterol Motil. 2016 Apr;22(2):181-92.

17 Reiter B, Kraft R, Günzel D, Zeissig S, Schulzke JD, Fromm M, et al. TRPV4-mediated regulation of epithelial permeability. FASEB J. 2006 Sep;20(11):1802-12.

18 Yamawaki H, Mihara H, Suzuki N, Nishizono $\mathrm{H}$, Uchida K, Watanabe S, et al. Role of transient receptor potential vanilloid 4 activation in indomethacin-induced intestinal damage. Am J Physiol Gastrointest Liver Physiol. 2014 Jul;307(1):G33-40.

19 Ishii M, Manabe N, Kusunoki H, Kamada T, Sato M, Imamura H, et al. Real-time evaluation of dyspeptic symptoms and gastric motility induced by duodenal acidification using noninvasive transnasal endoscopy. J Gastroenterol. 2008;43(12):935-41.

$20 \mathrm{Wu}$ Z, Wang S, Wu I, Mata M, Fink DJ. Activation of TLR-4 to produce tumour necrosis factor- $\alpha$ in neuropathic pain caused by paclitaxel. Eur J Pain. 2015 Aug;19(7):88998.

21 D'Aldebert E, Cenac N, Rousset P, Martin L, Rolland C, Chapman K, et al. Transient receptor potential vanilloid 4 activated inflammatory signals by intestinal epithelial cells and colitis in mice. Gastroenterology. 2011 Jan; 140(1):275-85.

22 Cenac N, Bautzova T, Le Faouder P, Veldhuis NA, Poole DP, Rolland C, et al. Quantification and Potential Functions of Endogenous Agonists of Transient Receptor Potential Channels in Patients With Irritable Bowel Syndrome. Gastroenterology. 2015;149:43344.e7.

23 McGuire C, Boundouki G, Hockley JR, Reed D, Cibert-Goton V, Peiris M, et al. Ex vivo study of human visceral nociceptors. Gut. 2018 Jan;67(1):86-96.

24 Alpizar YA, Boonen B, Sanchez A, Jung C, López-Requena A, Naert R, et al. TRPV4 activation triggers protective responses to bacterial lipopolysaccharides in airway epithelial cells. Nat Commun. 2017 Oct;8(1): 1059.

25 Segond von Banchet G, Boettger MK, König C, Iwakura Y, Bräuer R, Schaible HG. Neuronal IL-17 receptor upregulates TRPV4 but not TRPV1 receptors in DRG neurons and mediates mechanical but not thermal hyperalgesia. Mol Cell Neurosci. 2013Jan;52:15260.

26 Suzuki N, Mihara H, Nishizono H, Tominaga M, Sugiyama T. Protease-Activated Receptor-2 Up-Regulates Transient Receptor Potential Vanilloid 4 Function in Mouse Esophageal Keratinocyte. Dig Dis Sci. 2015 Dec; 60(12):3570-8 
27 Cenac N, Altier C, Motta JP, d'Aldebert E, Galeano S, Zamponi GW, et al. Potentiation of TRPV4 signalling by histamine and serotonin: an important mechanism for visceral hypersensitivity. Gut. 2010 Apr;59(4):4818.
28 Yang H, Duan Z. The Local Defender and Functional Mediator: gut Microbiome. Digestion. 2018;97(2):137-45.

29 Kato Y, Hiasa M, Ichikawa R, Hasuzawa N, Kadowaki A, Iwatsuki $\mathrm{K}$, et al. Identification of a vesicular ATP release inhibitor for the treatment of neuropathic and inflammatory pain. Proc Natl Acad Sci USA. 2017 Jul; 114(31):E6297-305.

30 Moriyama Y, Nomura M. Clodronate: A Vesicular ATP Release Blocker. Trends Pharmacol Sci. 2018 Jan;39(1):13-23. 